\title{
Effect of La, Mn and Ti doping on structural, dielectric, and magneticproperties of multiferroic $\mathrm{Bi}_{0.5} \mathrm{La}_{0.5} \mathrm{Fe}_{0.5} \mathrm{Mn}_{0.45} \mathrm{Ti}_{0.05} \mathrm{O}_{3}$
}

\author{
Rahul Singh, Prince K. Gupta Kaushal K. Shukla and Sandip Chatterjee* \\ Department of Physics, \\ Indian Institute of Technology (Banaras Hindu University), \\ Varanasi 221005, India \\ *Email: schatterji.app@iitbhu.ac.in
}

In recent years, multifunctional materials have attracted valuable interest due to the coexistence of more than two properties simultaneously in one material e.g. multiferroicity. $\mathrm{BiFeO}_{3}$ and $\mathrm{BiMnO}_{3}$ are two interesting multiferroic materials which show both ferroelectricity and magnetic ordering comparatively at higher temperature. In this investigation we have synthesized $\mathrm{Bi}_{0.5} \mathrm{La}_{0.5} \mathrm{Fe}_{0.5} \mathrm{Mn}_{1-\mathrm{x}} \mathrm{Ti}_{\mathrm{x}} \mathrm{O}_{3} \quad$ (where $\mathrm{x}=0 \%$ and $5 \%$ ). The Rietveld refinement of X-ray diffraction patterns shows that the systems crystallize in orthorhombic Pnma space group (Figure 1). Observed Raman modes support the XRD results. Appearance of prominent A1-3 and weak E-2 modes in $\mathrm{Bi}_{0.5} \mathrm{La}_{0.5} \mathrm{Fe}_{0.5} \mathrm{Mn}_{1}-\mathrm{xO}_{3}$ indicate the presence of chemically more active $\mathrm{Bi}-\mathrm{O}$ covalent bonds. Ferroelectricity of the system $\mathrm{Bi}_{0.5} \mathrm{La}_{0.5} \mathrm{Fe}_{0.5} \mathrm{Mn}_{1}-\mathrm{xO}_{3}$ is enhanced by Ti doped at Mn site (Figure 2 and 3).

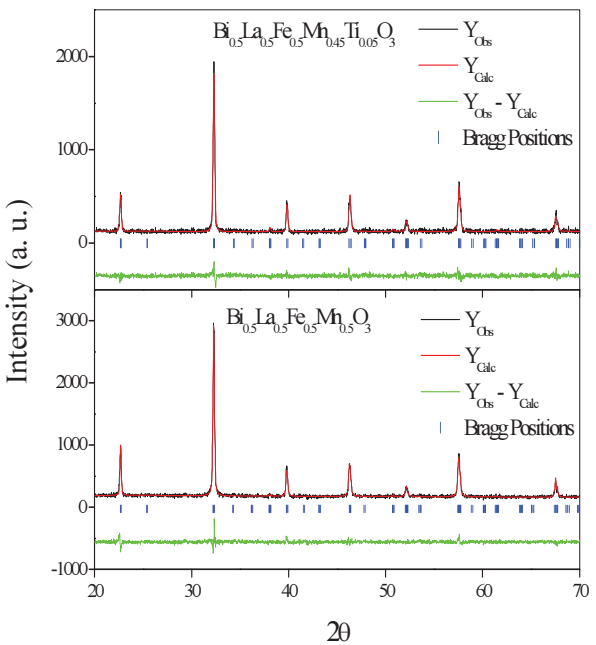

Figure 1: Rietveld refined X-ray diffraction patterns of $\mathrm{Bi}_{0.5} \mathrm{La}_{0.5} \mathrm{Fe}_{0.5} \mathrm{Mn}_{0.45} \mathrm{Ti}_{0.05} \mathrm{O}_{3}$.

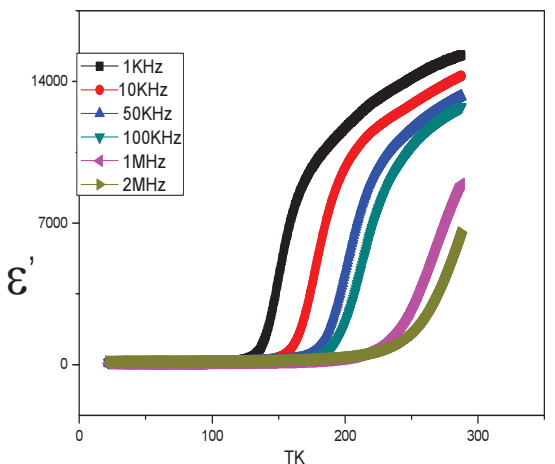

Figure 2: Variation in $\varepsilon$ for $\mathrm{Bi}_{0.5} \mathrm{La}_{0.5} \mathrm{Fe}_{0.5} \mathrm{Mn}_{0.45} \mathrm{Ti}_{0.05} \mathrm{O}_{3}$ at various frequencies as a function of temperature.

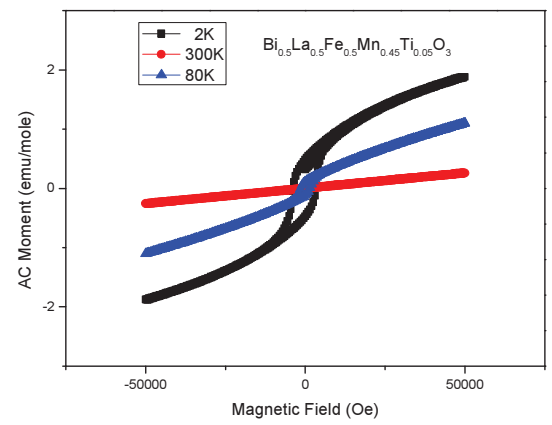

Figure 3: M-H loops of $\mathrm{Bi}_{0.5} \mathrm{La}_{0.5} \mathrm{Fe}_{0.5} \mathrm{Mn}_{0.45} \mathrm{Ti}_{0.05} \mathrm{O}_{3}$ at different temperatures.

\section{Reference}

1. Rahul Singh,G. D. Dwivedi,P. Shahi,D. Kumar,Om Prakash,A. K. Ghosh,and Sandip Chatterjee, Journal Of Applied Physics1 15, 134102 (2014).

1. A. K. Ghosh, G. D. Dwivedi, B. Chatterjee, B. Rana, A. Barman, S.Chatterjee, and H. D. Yang,Solid State Commun.166, 22 (2013). 